that women do not like the intravenous drip. It is certainly easy to use and can be ordered over the telephone. Whether women would prefer the limitations imposed by the lozenges for from 24 to 48 hours to a $1: 5$ chance of a drip is not known, but they would all opt for the method which is safest for their unborn child. In my view the buccal route is retrograde for four reasons: (1) it involves the use of heroic amounts of oxytocin; (2) its rate of absorption from the buccal mucous membrane is unknown and varies from patient to patient and probably from hour to hour in any given patient; (3) unless the woman is " ready" to go into labour the sensitivity of her myometrium must increase to oxytocin and often at the very time that the amount of oxytocin being absorbed is also increasing, and nobody can believe that this dangerous " crossing" of the levels can be speedily countered by removing the lozenge ; and (4) it differs little from the old and discarded nasal route and is therefore historically retrograde.

The buccal route cannot be justified on theoretical grounds, and its record in this country is already calamitous and may prove so disastrous as once more to stir up opposition to the use of oxytocin until the birth of the child is imminent.-I am, etc.,

\section{University College Hospital,}

$$
\text { G. W. Theobald. }
$$

\section{RIPERENCES}

1 Theobald, G. W., in British Obstetric Practice, ed. A. Claye, p. 1055, 3rd ed., 1963. Heinemann, London.

2 Caldeyro-Barcia, R., 1964, personal communication.

3 Hendricks, C. H., 1964, personal communication.

\section{Hospitals for Subnormal Patients}

SIR,-For various reasons it has been stated that $400-500$ beds is to be the optimum for a hospital for subnormal and severely subnormal patients. The validity of some of these reasons can be questioned, and it is doubtful whether hospitals of this size can properly fulfil their appropriate functions, which are to be a social training ground, a shelter, a school, a place of control, a community as well as being a hospital in the best sense of the word where these patients can receive expert medical and nursing care and where fundamental research and inquiry can be made into the aetiology, pathology, and prevention of mental deficiency.

As secondary functions, the hospital should serve as a training school for all grades of staff required in such hospitals, and as an orientation centre for students in the disciplines of medicine, psychology, nursing, education, and social science. There should also be links with the nearest university and teaching school in all the above disciplines, and also with local authorities by the provision of out-patients clinics, both intra- and extramural, and on all matters connected with the retarded, such as aid in ascertainment, investigation, diagnosis, prognosis, and disposal.

The hospital should also serve as an investigation centre so that medical men, local authorities, magistrates, children's officers, and parents themselves can be advised on matters concerning the retarded. It should also be the centre of its area for the temporary relief of any acute or chronic disorder in the retarded.
A review of the Hospital Year Book 1965 shows as follows -208 hospitals or units housing the retarded can be identified. Of these 103 have less than 100 beds (average 44), another 30 have less than 200 (average 151), while the total with less than 500 beds is 172 or $82 \%$ of the whole. At the other end of the scale, only 18 hospitals are shown as having 750 beds or more. Such statements as "It has for too long been the custom to house mental defectives in over-large, gloomy, remote institutions, etc." in view of these figures would not appear to be wholly true.

Consideration should be given as to whether hospitals of the size now being planned by the Ministry can in fact carry out their proper functions, whether they will attract staff of the right calibre, and whether if they are given the necessary facilities to carry out all their functions they will indeed be financially realistic. There is no proof that the majority of smaller hospitals have in the past contributed more to the study of mental subnormality than have the larger hospitals, and there is no proof that the smaller the hospital the more efficient does it become.

It seems more than doubtful whether new hospitals of 400 beds will ever become viable enough to fulfil their basic functions. The viability of these hospitals will also be in doubt whenever they come within the administrative control of a general or mixed group of hospitals as appears to be the growing pattern. Hospitals for subnormal patients require an expertise and a specialized emotional approach among members of management committees if the same sound basic principles of medicine, psychology, nursing, education, and the social sciences as they apply to normal individuals are to apply, as of right, to the retarded.

Such expertise and approach are best found in management committees who specialize in this work.-I am, etc., GEORGE
The Prudhoe and Monkton Hospital,
Northumberland. Grorge McCoull.

\section{Implantation Dermoid of Neck}

SIR,-Implantation dermoids commonly occur in hand or sole, though they can be encountered elsewhere too. Here it is desired to put on record a case of implantation dermoid occurring in the neck after excision of submandibular salivary gland.

Mr. A. B., age 49 years, was seen with an unusual lump in left side of his neck. It had appeared 14 weeks after the excision of his left submandibular salivary gland for a calculus, under the scar. This lump was $5 \times 2.5 \mathrm{~cm}$. in size and moved with deglutition. It felt doughy and could be indented like putty, becoming prominent again after a few acts of swallowing. It was quite painless and there was no bruit over it, nor was there any history of dysphagia or regurgitation of food material suggestive of a pharyngeal pouch. The swelling did not alter in any way during a period of observation of six weeks and consequently it was explored.

After deepening the incision through platysma a very large cyst was encountered with a welldefined capsule. This cyst was filling the whole of the region formerly occupied by the submandibular gland and was extending backwards and upwards into the ront of the neck and forwards into the floor of the mouth. It had only one firm attachment which was anterinrly on the hyoglossus deep to the mylohyoid muscle-hence the mobility with deglutition. The cyst was enucleated without difficulty.

On opening, the cyst was found to contain faecal-looking brownish material of the consistency of sebum. On microscopy the section showed the cyst to be lined by epidermis and to contain a large amount of keratin. There were some foreign-body giant-cells outside the cyst, and mild chronic inflammatory cell infiluration outside the cyst wall. The appearances were those of an epidermoid cyst consistent with implantation.

I am thankful to Mr. J. G. Jamieson for allowing me to publish this case.

-I am, etc.,

Dryburn Hospital,
Durham.

S. K. Agrawal.

\section{Delays in Out-patients}

SIR,-Dr. G. W. Garland (2 January, p. 57) asks why so many consultants limit their clinics. It may be that after $3 \frac{1}{2}$ to 4 hours in a clinic most consultants feel that they can no longer give an opinion of value.I am, etc.,

Bournemouth, Hants.

SIR,-I would like to support Dr. G. W. Garland's view (2 January, p. 57) that consultants have some responsibility in this matter.

For the past year I have made it a routine at each out-patient clinic to note on my appointments list the date of each general practitioner's letter and the number of days elapsing before the patient was seen. Whenever the delay reached 14 days, the appointments office was instructed to increase the number of new patients seen at each clinic by one or, if necessary, two. I have found that this modest increase was required only for a few weeks from time to time during the year and it has almost completely eliminated delays of more than 14 days.

If it were generally adopted, this simple measure would greatly ameliorate a problem which is becoming a serious reproach to the National Health Service.-I am, etc.,

Whittington Hospital, A. L. JACOBS.

London N.19.

\section{Education in First Aid}

SIR,-In reply to Mr. N. Capener (19 December, p. 1596) health education in schools has always been encouraged by the central department-i.e., Board, Ministry, and now Department of Education and Science, and a H.M.I. is responsible for the subject. There is also a publication, Health Education, ${ }^{1}$ which in its successive editions has kept pace with medical and educational thought. The last edition includes a chapter on accident prevention, and it states that simple facts about first aid should be within the grasp of every boy and girl of secondary school age. A warning is added, however, that inadequate first aid does more harm than good, and the question is asked, "Does the staff include anyone with real knowledge and experience of the subject ?" Similarly a current textbook for student teachers remarks (p. 237, " First aid . . . can be a most helpful introduction to 